\title{
Catecholamine response to exercise in individuals with different levels of paraplegia
}

\footnotetext{
L.L. Steinberg ${ }^{1}$,

F.A.A. Lauro ${ }^{1}$,

M.M.M. Sposito²,

S. Tufik ${ }^{3}$, M.T. Mello ${ }^{6}$,

M.G. Naffah-M azzacoratti ${ }^{4}$,

E.A. Cavalheiro ${ }^{5}$ and

A.C. Silva ${ }^{1}$
}

\author{
Departamentos de ${ }^{1}$ Fisiologia, ${ }^{2} \mathrm{O}$ tolaringologia, ${ }^{3} \mathrm{Psicobiologia},{ }^{4} \mathrm{Bioquímica}$, and \\ ${ }^{5}$ Neurologia, Escola Paulista de Medicina, Universidade Federal de São Paulo, \\ São Paulo, SP, Brasil \\ ${ }^{6}$ Departamento de Educação Física e Esportes, Universidade Federal de U berlândia, \\ U berlândia, MG, Brasil
}

\section{Correspondence \\ A.C. Silva \\ Departamento de Fisiologia EPM, UNIFESP \\ Rua Botucatu, 852, 50 andar 04023-900 São Paulo, SP \\ Brasil \\ Fax: +55-11-229-5906 \\ E-mail: anton.fisi@epm.br \\ Research supported by FAPESP, INDESP, and AFIP.}

Received April 23, 1999 Accepted May 3, 2000

\begin{abstract}
The purpose of this study was to investigate the effect of the level of injury on the serum level of norepinephrine (Nor) and epinephrine (Epi) at rest and after maximal exercise in individuals with paraplegia. Twenty-six male spinal cord-injured subjects with complete paraplegia for at least 9 months were divided into two groups of 13 subjects each according to the level of injury, i.e., T1-T6 and T7-T12. Serum Nor and Epi concentrations were measured by HPLC-ECD, at rest (PRE) and immediately after a maximal ergospirometric test (POST). Statistical analysis was performed using parametric and non-parametric tests. Maximal heart rate, peak oxygen uptake, and PRE and POST Nor were lower in the T1-T6 than in the T7-T12 group (166 $\pm 28 \mathrm{vs} 188$ $\pm 10 \mathrm{bpm} ; 18.0 \pm 6.0$ vs $25.8 \pm 4.1 \mathrm{ml} \mathrm{kg}^{-1} \mathrm{~min}^{-1} ; 0.54 \pm 0.26$ vs 0.99 $\pm 0.47 \mathrm{nM} ; 1.48 \pm 1.65$ vs $3.07 \pm 1.44 \mathrm{nM}$ ). Both groups presented a significant increase in Nor level after exercise, while only the T7-T12 group showed a significant increase in Epi after exercise (T1-T6: 0.98 \pm 0.72 vs $1.11 \pm 1.19 \mathrm{nM}$; T7-T12: $1.24 \pm 1.02$ vs $1.89 \pm 1.57 \mathrm{nM})$. These data show that individuals with paraplegia above T6 have an attentuated catecholamine release at rest and response to exercise as compared to subjects with injuries below T6, which might prevent a better exercise performance in the former group.
\end{abstract}

\section{Introduction}

The sympathetic nervous system (SNS) controls cardiovascular responses during postural changes and exercise (1). Physical exercise can impose a significant stress on the organism, and the extent of the response depends on several factors such as exercise intensity and duration and training status of the individual (2-4). Catecholamines are both

\section{Key words}

- Catecholamines

- Paraplegia

- Exercise

- Norepinephrine

- Epinephrine

- Spinal cord injury neurotransmitters and hormones, and play a dominant role in helping the individual respond to the stress of exercise $(1,4)$. Among these responses are the capacity to control cardiac function and metabolism, to control blood flow in the working muscles, and substrate mobilization and utilization (4-6). During the course of a progressive maximal exercise test, peripheral catecholamines increase exponentially with increasing work- 
load (7). The measurement of blood norepinephrine (Nor) can be used to estimate SNS activity (8), since it reflects its release at the nerve terminals $(2,9)$. On the other hand, the activity of the adrenal glands can be evaluated by the measurement of blood epinephrine (Epi) (6).

Spinal cord injury (SCI) above T7 leads to an impairment of the SNS function due to the loss of transmission of efferent signals from supraspinal centers to the periphery, and of afferent signals back to the central nervous system, and its severity depends on the level and completeness of injury (10-12). Several investigators have reported lower blood levels of Nor and Epi for quadriplegics at rest $(10,11,13,14)$, during tilting $(10$, $15,16)$ and exercise $(12,17)$. It has already been established that quadriplegics have an impairment of peripheral SNS activation that justifies their lack of catecholamine response to exercise, but they also have a less active muscle mass in the upper extremities that might contribute to these findings.

In recent years some studies have been conducted to evaluate the catecholamine responses to exercise in paraplegics $(18,19)$, but discrepancies have been found. Although there is evidence that individuals with paraplegia above T6 have an impaired catecholamine response to tilting (10) and exercise $(18-20)$, the degree of such impairment is still controversial, with some authors reporting the absence of a catecholamine response to exercise in individuals with injury above T6 (18), and others reporting normal Nor release for the same group (19).

The purpose of this study was to investigate the effect of the level of injury on the serum level of Nor and Epi at rest (PRE) and after maximal exercise (POST) in subjects with different levels of paraplegia.

\section{Material and Methods}

Twenty-six subjects with complete SCI (ASIA grade A) (21) with upper motor neu- ron lesion between $\mathrm{T} 1$ and $\mathrm{T} 12$ volunteered for the research. All gave their written informed consent to participate in a protocol approved by the Ethics Committee for human experimentation, and each subject was screened by medical history, physical examination, 12-lead resting electrocardiogram and spirometric tests. Subjects with any contraindication for maximal physical activity or taking any medication that could affect the physiological responses to exercise were excluded from the study.

All were males and the cause of injury was traumatic in all but two cases; their age ranged from 17 to 58 years and all had sustained their injury at least 9 months before the study. The subjects were divided into two groups of 13 subjects each according to the level of injury, T1-T6 and T7-T12, and were matched for age, time since injury and weight (Table 1).

\section{Procedure}

The subjects arrived at the laboratory at 8:00 a.m. after a 12-h fast. At arrival, they ate a standard breakfast consisting of $50 \mathrm{~g}$ of bread, $10 \mathrm{~g}$ of cheese, $10 \mathrm{~g}$ of ham and 200 $\mathrm{ml}$ of orange juice, in order to avoid exercise-related hypoglycemia. After a 30-min rest, the first blood sample was collected in the sitting position and the exercise test was performed.

All exercise tests were performed with an arm crank ergometer (Cybex MET300 ${ }^{\mathrm{TM}}$, Meadway, MA, USA), with the seat adapted in order to provide maximal stabilization of the trunk during the tests. The incremental test was started with 25 watts and was increased 12.5 watts every 2 min until exhaustion. An open circuit system was used to monitor the ventilatory and metabolic responses. The subjects breathed into a twoway valve (Hans Rudolph ${ }^{\mathrm{TM}}$, Kansas City, MO, USA) throughout the exercise tests. Expired ventilation rate $(1 / \mathrm{min})$, oxygen $\left(\mathrm{O}_{2}\right)$ and carbon dioxide $\left(\mathrm{CO}_{2}\right)$ concentrations 
were measured every $20 \mathrm{~s}$ with a Vista Metabolic System ${ }^{\mathrm{TM}}$ (Ventura, CA, USA), and the data were analyzed with a software designed for this purpose (Turbofit ${ }^{\mathrm{TM}}$, Ventura, CA, USA). Heart rate (HR) was recorded every $5 \mathrm{~s}$ with a heart rate monitor (Polar Vantage XL ${ }^{\mathrm{TM}}$, Kempele, Finland).

\section{Catecholamines}

Two blood samples $(10 \mathrm{ml})$ were collected from the antecubital vein at rest and immediately after the exercise test. Serum was obtained after clot retraction on ice (for no longer than $2 \mathrm{~h}$ ), centrifuged at $1500 \mathrm{~g}$ for $30 \mathrm{~min}$ and stored at $-80^{\circ} \mathrm{C}$ until the time for assay (no longer than 2 months). To quantify catecholamines, the sera were previously subjected to the following purification steps: $50 \mathrm{mg}$ of $\mathrm{Al}_{2} \mathrm{O}_{5}$ was weighed out in centrifuge tubes and $1-3 \mathrm{ml}$ of serum, $1.0 \mathrm{ml}$ of 2 $\mathrm{mol} / \mathrm{l}$ Tris- $\mathrm{HCl}, \mathrm{pH} 8.8$, and $40 \mu \mathrm{l}(8 \mathrm{ng})$ of dihydroxybenzylamine were added. The suspension was vortex-mixed for $10 \mathrm{~min}$, the alumina precipitate was washed three times and vortex-mixed with $1.0 \mathrm{ml}$ of water and the catecholamines eluted with $400 \mu 1$ of 0.1 $M$ perchloric acid after $1 \mathrm{~min}$ of vortexmixing. After centrifugation for $3 \mathrm{~min}$ at $1500 \mathrm{~g}$, the supernatant was filtered and 20 $\mu l$ injected into the reverse phase column. To study the recovery of catecholamines during alumina extraction, known amounts of Nor and Epi were added to the sera $(40 \mathrm{nmol})$ before alumina extraction and the mixture was processed as described. Catecholamine concentrations were determined by liquid chromatography with electrochemical detection (HPLC-ECD). The chromatographic parameters employed such as mobile phase, column, standard curves and retention time have been previously described $(22,23)$. Using the conditions described, the sera of able-bodied volunteers $(\mathrm{N}=22)$, age-matched to the subjects in the present study, presented values of $1.21 \pm 0.51 \mathrm{nM}$ for Nor and $1.04 \pm 0.49 \mathrm{nM}$ for Epi (mean \pm standard deviation). The recovery rate of catecholamines added to serum was $70 \%$ for all catecholamines studied $(\mathrm{N}=6)$. In a previous study from the same laboratory and using the same methodology, intra-assay coef-

Table 1 - Anthropometric data of subjects with complete paraplegia.

Sed.: Sedentary; Ath.: athlete (regularly involved in sports activity). There were no significant differences between groups (Mann-Whitney U-test).

\begin{tabular}{|c|c|c|c|c|c|c|c|c|c|c|c|}
\hline \multirow[t]{2}{*}{ Subject } & \multicolumn{5}{|c|}{ T1-T6 } & \multirow[t]{2}{*}{ Subject } & \multicolumn{5}{|c|}{ T7-T12 } \\
\hline & $\begin{array}{l}\text { Injury } \\
\text { level }\end{array}$ & $\begin{array}{c}\text { Age } \\
\text { (years) }\end{array}$ & $\begin{array}{c}\text { Time since } \\
\text { injury (months) }\end{array}$ & $\begin{array}{l}\text { Weight } \\
(\mathrm{kg})\end{array}$ & $\begin{array}{l}\text { Physical } \\
\text { activity }\end{array}$ & & $\begin{array}{l}\text { Injury } \\
\text { level }\end{array}$ & $\begin{array}{c}\text { Age } \\
\text { (years) }\end{array}$ & $\begin{array}{c}\text { Time since } \\
\text { injury (months) }\end{array}$ & $\begin{array}{l}\text { Weight } \\
(\mathrm{kg})\end{array}$ & $\begin{array}{r}\text { Physical } \\
\text { activity }\end{array}$ \\
\hline 1 & T3 & 37 & 204 & 57.0 & Sed. & 14 & T9 & 26 & 89 & 55.0 & Sed. \\
\hline 2 & T3 & 33 & 173 & 75.0 & Sed. & 15 & T10 & 34 & 83 & 58.0 & Sed. \\
\hline 3 & T5 & 48 & 60 & 88.0 & Sed. & 16 & T8 & 26 & 17 & 80.0 & Sed. \\
\hline 4 & T3 & 28 & 72 & 85.0 & Sed. & 17 & T10 & 22 & 11 & 47.6 & Sed. \\
\hline 5 & $\mathrm{~T} 4$ & 17 & 14 & 47.4 & Sed. & 18 & T12 & 49 & 132 & 73.0 & Sed. \\
\hline 6 & T4 & 58 & 186 & 58.0 & Sed. & 19 & $\mathrm{~T} 11$ & 31 & 108 & 50.0 & Sed. \\
\hline 7 & T6 & 26 & 46 & 60.2 & Sed. & 20 & T9 & 27 & 45 & 43.0 & Ath. \\
\hline 8 & $\mathrm{~T} 4$ & 25 & 9 & 72.0 & Sed. & 21 & T9 & 26 & 101 & 58.0 & Ath. \\
\hline 9 & T4 & 30 & 40 & 64.4 & Ath. & 22 & T11 & 22 & 132 & 68.0 & Ath. \\
\hline 10 & T3 & 27 & 93 & 82.0 & Ath. & 23 & T8 & 28 & 46 & 81.0 & Ath. \\
\hline 11 & $\mathrm{~T} 2$ & 30 & 135 & 65.0 & Ath. & 24 & $\mathrm{~T} 11$ & 31 & 38 & 68.0 & Sed. \\
\hline 12 & $\mathrm{~T} 4$ & 22 & 48 & 67.5 & Ath. & 25 & T9 & 30 & 71 & 65.0 & Ath. \\
\hline 13 & $\mathrm{~T} 1$ & 18 & 16 & 70.6 & Sed. & 26 & T12 & 28 & 114 & 69.4 & Ath. \\
\hline Mean & & 31 & 84 & 68.6 & & Mean & & 29 & 76 & 62.8 & \\
\hline SD & & 12 & 68 & 11.8 & & SD & & 7 & 41 & 12.0 & \\
\hline
\end{tabular}


ficient of variation for Nor and Epi were $6.3 \%$ and $7.4 \%$, respectively.

\section{Statistical analysis}

For the variables with Gaussian distribution (peak oxygen uptake $\left(\dot{\mathrm{V}}_{\text {2peak }}\right), \mathrm{HR}$ and weight) values were contrasted using a $t$-test for independent variables. Those variables that did not show a normal distribution (age, Nor and Epi) were assessed by the MannWhitney U-test for unpaired data (T1-T6 vs T7-T12) and the Wilcoxon rank test for paired independent data (PRE vs POST). All analyses were performed with a PC software (Graphpad Instat, San Diego, CA, USA) and the level of significance was set at $\mathrm{P} \leq 0.05$.

\section{Results}

\section{Physiological variables}

The physiological characteristics of the subjects are presented in Table $2 . \mathrm{VO}_{2 \text { peak }}$,

Table 2 - Physiological characteristics of paraplegic subjects divided according to the level of spinal cord injury.

$\mathrm{VO}_{\text {2peak: }}$ Peak oxygen uptake; $\mathrm{HR}_{\max }$ : maximal heart rate; $\mathrm{PO}_{\max }$ : maximal power output. $* \mathrm{P}<0.02,+\mathrm{P}<0.01$ compared to T1-T6 (t-test).

\begin{tabular}{lcccc}
\hline & $\mathrm{N}$ & $\dot{\mathrm{VO}}_{\text {2peak }}\left(\mathrm{ml} \mathrm{kg}^{-1} \mathrm{~min}^{-1}\right)$ & $\mathrm{HR}_{\max }(\mathrm{bpm})$ & $\mathrm{PO}_{\max }$ (watts) \\
\hline T1-T6 & 13 & $18.02 \pm 6.02$ & $166 \pm 28$ & $61 \pm 23$ \\
T7-T12 & 13 & $25.77 \pm 4.12^{+}$ & $188 \pm 10^{*}$ & $88 \pm 24 *$
\end{tabular}

Table 3 - Serum norepinephrine and epinephrine levels at rest (PRE) and immediately after maximal arm crank exercise (POST) in subjects with different levels of paraplegia.

Values are reported as mean $\pm \mathrm{SD}$. $* \mathrm{P}<0.0025$ compared to PRE (Wilcoxon test); ${ }^{\mathrm{P}}<0.003$ compared to T1-T6 (Mann-Whitney U-test).

Norepinephrine (nM)

\begin{tabular}{clc}
\hline T1-T6 & & \\
PRE & $0.54 \pm 0.26$ & $0.98 \pm 0.72$ \\
POST & $1.48 \pm 1.65^{*}$ & $1.11 \pm 1.19$ \\
T7-T12 & & \\
PRE & $0.99 \pm 0.47^{+}$ & $1.24 \pm 1.02$ \\
POST & $3.07 \pm 1.44^{*+}$ & $1.89 \pm 1.57^{*}$
\end{tabular}

maximal heart rate $\left(\mathrm{HR}_{\max }\right)$ and maximal power output $\left(\mathrm{PO}_{\max }\right)$ were significantly higher in the T7-T12 group than in the T1-T6 group.

\section{Norepinephrine}

Comparison of the two groups showed that PRE and POST Nor values were significantly higher in the T7-T12 group than in the T1-T6 group. Both groups showed a significant increase in Nor after maximal exercise (Table 3 ).

\section{Epinephrine}

The mean Epi values are presented in Table 3. There were no significant differences between the T1-T6 group and the T7T12 group pre-exercise. Only the T7-T12 group showed significantly increased Epi values after maximal exercise.

\section{Discussion}

For most of the measured data, the T1-T6 group showed lower values than the T7-T12 group, indicating an impairment in the activity of the peripheral SNS in subjects with paraplegia above T6.

In able-bodied subjects, as the intensity of physical activity increased, there is an overall increase in the activity of the SNS and a decrease in the activity of the parasympathetic nervous system (24-26), with their balance playing a role in controlling heart rate and contractility, in order to match the cardiovascular response to the intensity of physical activity. The impaired autonomic function in lesions above T6 reduces exercise capacity since it limits cardiac responses such as $\mathrm{HR}_{\max }$, contractility of the heart muscle, stroke volume and cardiac output $(20,27,28)$, especially at higher workloads (over 150-160 bpm) when the SNS plays a dominant role (25). This was further supported in the present study in which $\mathrm{HR}_{\max }$, 
$\dot{\mathrm{V}} \mathrm{O}_{2 \text { peak }}$ and $\mathrm{PO}_{\max }$ were significantly lower for the T1-T6 than the T7-T12 group, and the values for both groups were consistent with previous reports $(27,28)$.

At rest, Nor was lower for the T1-T6 group, while the T7-T12 group showed values similar to those obtained for able-bodied subjects in a previous report (22). Since Nor clearance is normal in persons with $\mathrm{SCI}(11)$, these low levels can be attributed to a reduction in peripheral sympathetic nervous activity due to the loss of transmission of impulses from and to supraspinal centers $(11,13)$.

Whereas both groups were able to increase serum Nor concentration after maximal exercise, the POST value was significantly lower in the T1-T6 group compared to the T7-T12 group. This finding is similar to those reported by Schmid et al. (19), while Frey et al. (18) found no significant increment in Nor after maximal exercise for T1T6 paraplegics. Although subjects in the study conducted by Frey et al. were considered active, their maximal power output was much lower than in our study and Schmid's (respectively 34, 59 and 66 watts) and this difference could explain the discrepancy found. Our results are lower than those reported by Schmid et al. (19) for T1-T4 paraplegics (1.48 vs $4.52 \mathrm{nM}$ ), probably because of the differences in methodology, since these investigators determined catecholamine concentrations radioenzymatically from arterialized venous blood while we used venous blood from an antecubital vein. The T7-T12 group showed an average threefold increase in Nor similar to able-bodied subjects during wheelchair ergometry (19) but lower than the 5-40-fold increase reported for able-bodied subjects during leg exercise $(1,4,12)$. This is related to the type of exercise, since during maximal exercise Nor secretion is related to the working muscle mass $(5,7,29)$.

Innervation of the adrenal medulla, the primary source of circulating Epi, derives from the T5-T11 levels (12). The present study showed that only subjects with partially or completely intact adrenal medulla innervation were able to increase serum Epi concentration during exercise, although this concentration was much lower than those reported for able-bodied subjects during arm exercise $(6,29)$. Frey et al. (18) obtained similar results when investigating the catecholamine and lactate responses to maximal exercise in paraplegics and tetraplegics; while paraplegics with injuries between T10-T12 demonstrated sympathoadrenal patterns similar to, but lower than those of able-bodied subjects, persons with SCI between C7-T2 exhibited hyposympathoadrenal function and dissociation between catecholamine activity and lactate production, indicating that other compensatory factors contribute to muscle glycogenolysis in individuals with high-level SCI (18).

Our data show that individuals with paraplegia above $\mathrm{T} 6$ have an attentuated catecholamine release at rest and response to exercise as compared to subjects with injuries below $\mathrm{T} 6$, which might prevent a better exercise performance in this group.

\section{Acknowledgments}

The authors gratefully acknowledge Dr. Pablius Silva, Dr. Fernando Torres, Dr. Francisco P. Almeida, Prof. Yara Juliano, and Prof. Neil Ferreira Novo for technical assistance. 


\section{References}

1. Christensen NJ \& Galbo H (1983). Sympathetic nervous activity during exercise. Annual Review of Physiology, 45: 139153.

2. Péronnet $D A$, Cléroux $J$, Perrault $H$, Cousineau D, Dechamplain J \& Nadeau R (1981). Serum norepinephrine response to exercise before and after training in humans. J ournal of Applied Physiology, 51: 812-815.

3. Green J H (1990). The Autonomic Nervous System and Exercise. Chapman and Hall, London.

4. Mazzeo RS (1991). Catecholamine responses to acute and chronic exercise. Medicine and Science in Sports and Exercise, 23: 839-845.

5. Savard GK, Richter EA, Strange $S$, Kiens B, Christensen NJ \& Saltin B (1989). Norepinephrine spillover from skeletal muscle during exercise in humans: role of muscle mass. American J ournal of Physiology, 257: H812-H818.

6. Hooker SP, Wells CL, Manore MM, Philip SA \& Martin N (1990). Differences in epinephrine and substrate responses between arm and leg exercise. Medicine and Science in Sports and Exercise, 22: 779-784.

7. Mazzeo RS \& Marshall P (1989). Influence of serum catecholamines on the lactate threshold during graded exercise. J ournal of Applied Physiology, 67: 1319-1322.

8. Savard G, Strange S, Kiens B, Richter EA, Christensen NJ \& Saltin B (1987). Noradrenaline spillover during exercise in active versus resting skeletal muscle in man. Acta Physiologica Scandinavica, 131: 507515.

9. Rea RF, Eckberg DL, Fritsch J M \& Goldstein DS (1990). Relation of serum norepinephrine and sympathetic traffic during hypotension in humans. American J ournal of Physiology, 258: R982-R986.

10. Guttmann L, Munro AF, Robinson R \& Walsh JJ (1963). Effect of tilting on the cardiovascular responses and serum catecholamine levels in spinal man. Paraplegia, 1: 4-18.

11. Krum H, Brown DJ, Rowe PR, Louis WJ \& Howes LG (1990). Steady state serum
[3H]-noradrenaline kinetics in quadriplegic chronic spinal cord injury patients. J ournal of Autonomic Pharmacology, 10: 221-226.

12. Bloomfield SA, J ackson RD \& Mysiw WJ (1994). Catecholamine response to exercise and training in individuals with spinal cord injury. Medicine and Science in Sports and Exercise, 26: 1213-1219.

13. DeBarge O, Christensen NJ , Corbett J L, Eidelman $\mathrm{BH}$, Frankel $\mathrm{HL} \&$ Mathias $\mathrm{CJ}$ (1974). Serum catecholamines in tetraplegics. Paraplegia, 12: 44-49.

14. Koh J, Brown TE, Beightol LA, Ha CY \& Eckberg DL (1994). Human autonomic rhythms: vagal cardiac mechanisms in tetraplegic subjects. J ournal of Physiology, 474: 483-495.

15. Mathias CJ, Christensen NJ , Corbett J L, Frankel HL, Goodwin TJ \& Peart WS (1975). Serum catecholamines, serum renin activity and serum aldosterone in tetraplegic man, horizontal and tilted. Clinical Science and Molecular Medicine, 49: 291-299.

16. Kamelhar DL, Steele JM, Schacht RG, Lowenstein J \& Naftchi E (1978). Serum renin and serum dopamine-ß-hydroxylase during orthostatic hypotension in quadriplegic man. Archives of Physical Medicine and Rehabilitation, 59: 212-216.

17. Wheeler G, Cumming D, Burnham R, McLean I, Sloley BD, Bhambhani $Y$ \& Steadward RD (1994). Testosterone, cortisol and catecholamine responses to exercise stress and autonomic dysreflexia in elite quadriplegic athletes. Paraplegia, 32: 292-299.

18. Frey GC, McCubbin J A, Dunn J M \& Mazzeo RS (1997). Plasma catecholamine and lactate relationship during graded exercise in men with spinal cord injury. Medicine and Science in Sports and Exercise, 29: 451-456.

19. Schmid A, Huonker M, Barturen J M, Stahl F, Schmidt-Trucksäss A, König D, Grathwohl D, Lehmann M \& Keul J (1998). Catecholamines, heart rate, and oxygen uptake during exercise in persons with spinal cord injury. J ournal of Applied Physiology, 85: 635-641.
20. Ragnarsson KT (1993). The cardiovascular system. In: Whiteneck GG (Editor), Aging with Spinal Cord Injury. Demos Publications, New York, 73-92.

21. Diturnno J r J F (1992). Standards for Neurological and Functional Classification of Spinal Cord Injury. American Spinal Injury Association, Chicago, IL.

22. Naffah-Mazzacoratti MG, Casarini DE, Fernandes MJ S \& Cavalheiro EA (1992). Serum catecholamine levels determined by high performance liquid chromatography coupled with electrochemical detection. Arquivos Brasileiros de Endocrinologia e Metabolismo, 36: 119-122.

23. Cavalheiro EA, Fernandes MJ , Turski L \& Naffah-M azzacoratti MG (1994). Spontaneous recurrent seizures in rats: amino acid and monoamine determination in the hippocampus. Epilepsy, 35: 1-11.

24. Araújo CGS (1985). Fast "ON" and "OFF" heart rate transients at different bicycle exercise levels. International J ournal of Sports Medicine, 6: 68-73.

25. Raven PB \& Hagan RD (1994). Cardiovascular responses to exercise and training. In: Harries M, Williams C, Stanish WD \& Micheli LJ (Editors), Oxford Textbook of Sports Medicine. Oxford University Press, New York, 149-160.

26. Gallo J r L, Maciel BC, Marin-Neto J A, Martins LEB, Lima-Filho EC, Golfetti R, Chacon MPT \& Forti VAM (1995). Control of heart rate during exercise in health and disease. Brazilian J ournal of Medical and Biological Research, 28: 1179-1184.

27. Coutts KD, Rhodes EC \& McKenzie DC (1983). Maximal exercise response of tetraplegics and paraplegics. Journal of Applied Physiology, 55: 479-482.

28. Davis GM (1993). Exercise capacity of individuals with paraplegia. Medicine and Science in Sports and Exercise, 25: 423432.

29. Blomqvist CG, Lewis SF, Taylor WF \& Graham RM (1981). Similarity of the hemodynamic responses to static and dynamic exercise of small muscle groups. Circulation Research, 48: I-87-I-92. 